\title{
A New Method for Optimal Solutions of Transportation Problems in LPP
}

\author{
Muhammad Hanif ${ }^{1} \&$ Farzana Sultana Rafi ${ }^{2}$ \\ ${ }^{1}$ Professor, Department of Applied Mathematics, Noakhali Science and Technology University, Noakhali 3814, \\ Bangladesh \\ ${ }^{2}$ Lecturer in Mathematics, Department of Computer Science and Engineering, University of South Asia, Dhaka 1213, \\ Bangladesh
}

Correspondence: Muhammad Hanif, Professor, Department of Applied Mathematics, Noakhali Science and Technology University, Noakhali 3814, Bangladesh.

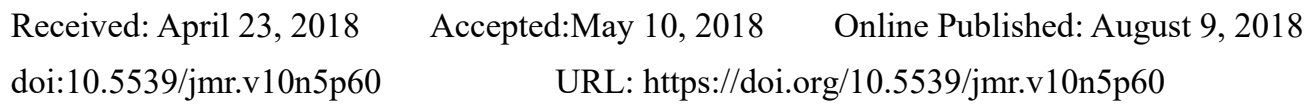

\begin{abstract}
The several standard and the existing proposed methods for optimality of transportation problems in linear programming problem are available. In this paper, we considered all standard and existing proposed methods and then we proposed a new method for optimal solution of transportation problems. The most attractive feature of this method is that it requires very simple arithmetical and logical calculation, that's why it is very easy even for layman to understand and use. Some limitations and recommendations of future works are also mentioned of the proposed method. Several numerical examples have been illustrated, those gives the clear idea about the method. A programming code for this method has been written in Appendix of the paper.
\end{abstract}

Keywords: linear programming, transportation problems, different optimization methods, matlab coding

Mathematics Classification Subject (2010): 49Mxx, 65Kxx, 90Bxx, 90Cxx

\section{Introduction}

The transportation problem is one of the earliest and most important applications of linear programming problem. It is a particular class of linear programming, which is associated with day- to-day activities in our real life and mainly deals with logistics. A certain amount of homogeneous commodity is available at number of sources and a fixed amount is required to meet the demand at each number of destinations. Business and Industries are practically faced with both economic optimizations such as cost minimization of non-economic items that are vital to the existence of their firms. The Transportation Models or Problems are primarily concerned with the optimal (best possible) way in which a product produced at different factories or plants (called supply origins) can be transported to a number of warehouses or customers (called demand destinations). The finding an optimal schedule of shipment of the commodity with the satisfaction of demands at each destination is the main goal of the problem. The origin of transportation Problem was first presented by American famous mathematician Alfred Hitchcock (1899-1980) in 1941. There are several algorithms delete this bracket such as Northwest Corner Rule, Least Cost Method, Vogel's Approximation Method, Row Minimum Method, Column Minimum Method, Modified Distribution (MODI) Method, Stepping Stone Method for solving transportation problems which are based on different of special linear programming methods. Basically, these methods are different in term of the quality for the produced basic starting solution and the best starting solution that yields smaller objective value. There have been also many methods delete this bracket proposed such as ASM Method, Best Candidates Method (BCM), Zero Suffix Method, ATM Method to optimize the cost of transportation problems. The value of the objective function obtained by such proposed method is same or minimum than the optimal value obtained by established solution techniques. 


\section{Preliminaries}

\subsection{Network Representation Transportation Problems}

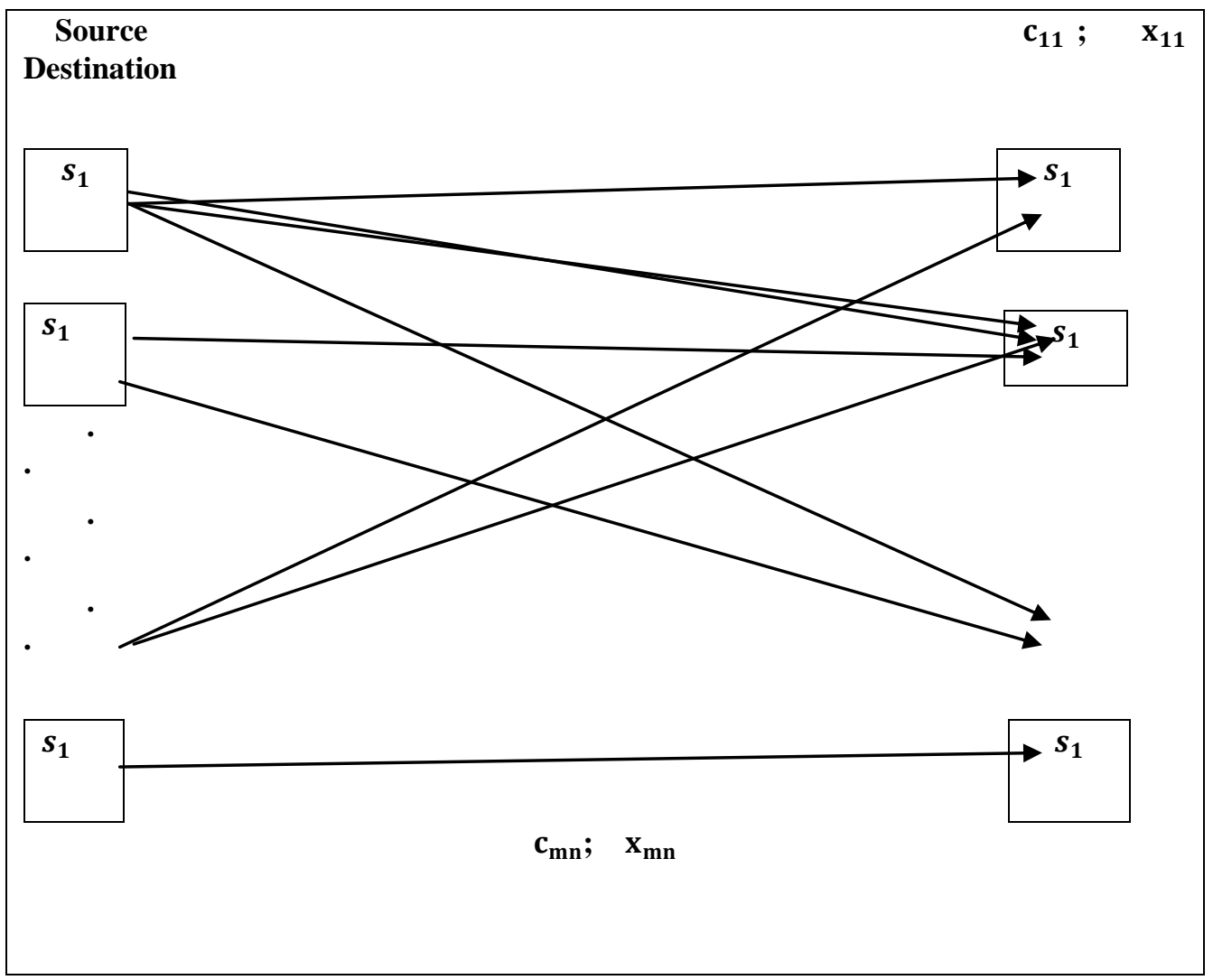

Figure 2.1. Network representation of Transportation Problems.

\subsection{Mathematical model Transportation Problems}

The following notation is used for the mathematical representation of the Transportation Problem. For each source point $\mathrm{i}$ $(\mathrm{i}=1,2, \ldots, \ldots, \mathrm{m})$ and destination point $\mathrm{j}(\mathrm{j}=1,2, \ldots \ldots, \mathrm{n})$;

$\mathrm{m}=$ number of source;

$\mathrm{n}=$ number of destination;

$a_{i}=$ amount of supply at source $\mathrm{i}$;

$b_{j}=$ amount of demand at destination $\mathrm{j}$;

$c_{i j}=$ unit transportation cost between source $\mathrm{i}$ and destination $\mathrm{j}$;

$x_{i j}=$ amount of homogeneous product transported from source $\mathrm{i}$ and destination $\mathrm{j}$.

Using the above notations, the Transportation Problem can be expressed in

Mathematical term as finding a set of $x_{i j}$ 's, $\quad \mathrm{i}=1,2, \ldots \ldots, \mathrm{m} ; \mathrm{j}=1,2, \ldots \ldots, \mathrm{n}$ toMinimize $\mathrm{Z}=\sum_{i=1}^{m} \sum_{j=1}^{n} c_{i j} x_{i j}$

Subject to the constraints:

$$
\begin{array}{rlrl}
\sum_{j=1}^{n} x_{i j} & =a_{i} ; & \mathrm{i}=1,2, \ldots \ldots, \mathrm{m} \\
\sum_{j=1}^{n} x_{i j}=b_{j} ; & \mathrm{j}=1,2, \ldots \ldots, \mathrm{n} \\
x_{i j} \geq 0 & & \text { For all } \mathrm{i} \text { and } \mathrm{j}
\end{array}
$$




\subsection{Basic Definitions of Transportation Problems}

Feasible Solution (F.S): A set of non negative allocation $x_{i j} \geq 0$ which satisfies the row and column restriction is known as Feasible Solution.

Basic Feasible Solution (BFS): A feasible solution to an $m$ - origins and $n$-destination problem is said to be Basic Feasible Solution if the number of positive allocation are $(m+n-1)$. If the number of allocations in basic feasible solution are less than $(m+n-1)$, it is called Degenerate Basic Feasible Solution (DBFS) otherwise non-degenerate.

Degenerate Basic Feasible Solution: A basic feasible solution that contains less than $m+n-1$ non-negative allocation.

Optimal Solution: A feasible solution (not necessarily basic) is said to be Optimal if minimizes the total transportation cost.

Optimality test: Optimality test can be performed if "the number of allocation cells in an initial basic feasible solution = $\mathrm{m}+\mathrm{n}-1$ (no. of rows + no. of columns -1 )". Otherwise the optimality test cannot be performed.

Cell: It is a small compartment in the transportation tableau. Circuit: A circuit is a sequence of cells (in the balanced transportation tableau) such that (i) It starts and ends with the same cell. (ii) Each cell in the sequence can be connected to the next member by a horizontal or vertical line in the tableau.

Allocation: The number of units of items transported from a source to a destination which is recorded in a cell in the transportation tableau.

Basic Variables: The variables in a basic solution whose values are obtained as the simultaneous solution of the system of equations that comprise the functional constraints.

The Constraints: The constraints are the conditions that force supply and demand needs to be satisfied. In a Transportation Problem, there is one constraint for each node.

i) The supply at each source must be used:

$$
\sum_{j=1}^{n} x_{i j}=a_{i}, \mathrm{i}=1,2,3, \ldots \ldots, \mathrm{m} ;
$$

ii) The demand at each destination must be met:

$$
\sum_{i=1}^{m} x_{i j}=b_{j}, j=1,2,3, \ldots \ldots, m ;
$$

iii) Non negativity:

$$
x_{i j} \geq 0, \text { for all } i \text { and } j .
$$

\subsection{Classifications of Transportation Problems}

Balanced Transportation Problem: A Transportation Problem is said to be balanced Transportation Problem if total number of supply is same as total number of demand.

Unbalanced Transportation Problem: A Transportation Problem is said to be unbalanced Transportation Problem if total number of supply is not same as total number of demand.

\section{Algorithm of Proposed Method}

The Method starts in the cell (route) corresponding to the south-west corner, or the upper right, of the tableau (variable). Below is a description of the steps:

Step 1: Select the south west (upper right-hand) corner cell of the transportation table and allocate as many units as possible equal to the minimum between available supply and demand requirements.

Step 2: Exit the row or the column when the supply or demand reaches zero and cross it out, to show that we cannot make any more allocations to that row or column. If both row and column simultaneously reach zero, cross out both row and column and then again select the south-west (upper right-hand) corner cell of the remaining transportation table and allocate the minimum between available supply and demand requirements.

Step 3: If exactly one row or column is left that is not crossed out, stop. Otherwise, advance to the cell in that row or column which is minimum. If in the left row (or column) all cells are same then select the cell of minimum number of column (or row).

Step 4: Continue the procedure until the total available quantity is fully allocated to the cells as required.

\section{Numerical Examples}

Here we tested our proposed method by considering the different numerical examples and verified our results with standard transportation methods. 


\section{Example 1}

Construct a transportation table to calculate the feasible solution.

\begin{tabular}{|l|l|l|l|l|}
\hline From & Do & E & F & Supply \\
\hline A & 6 & 4 & 1 & 50 \\
\hline B & 3 & 8 & 7 & 40 \\
\hline C & 4 & 4 & 2 & 60 \\
\hline Demand & 20 & 95 & 35 & 150 \\
\hline
\end{tabular}

Table 4.1(a). Transportation Table of Example 1

Iteration 1:

Select the south-west cell 1. Allocate the minimum between available supply and demand (50, 20). Exit the column since required demand reaches zero and cross it out. We cannot make any more allocations to that column.

\begin{tabular}{|c|c|c|c|c|}
\hline From & $\mathrm{D}$ & $\mathrm{E}$ & $\mathrm{F}$ & Supply \\
\hline A & 6 & 4 & \begin{tabular}{l|}
1 \\
35
\end{tabular} & $50 / 15$ \\
\hline B & 3 & 8 & 7 & 40 \\
\hline $\mathrm{C}$ & 4 & 4 & 2 & 60 \\
\hline Demand & 20 & 95 & $35 / 0$ & 150 \\
\hline
\end{tabular}

Table 4.1(b). Iteration 1 of example 1

Iteration 2:

Advance in the row that is not crossed out to the cell which is minimum. Here we select 4 and allocate min (15, 95). Cross out the row since it reaches zero.

\begin{tabular}{|c|c|c|c|c|}
\hline $\mathrm{from}_{\text {fro }}^{\text {To }}$ & $\mathrm{D}$ & $\mathrm{E}$ & $\mathrm{F}$ & Supply \\
\hline A & 6 & 4 & 1 & $50 / 15 / 0$ \\
\hline & & $\overline{115}$ & 35 & \\
\hline B & 3 & 8 & 7 & 40 \\
\hline $\mathrm{C}$ & 4 & 4 & 2 & 60 \\
\hline Demand & 20 & $95 / 80$ & $35 / 0$ & 150 \\
\hline
\end{tabular}

Table 4.1(c). Iteration 2 of example 1 
Iteration 3:

In the remaining column, minimum cell is 4 and allocate min $(60,80)$. Cross out the row since it reaches zero.

\begin{tabular}{|c|c|c|c|c|}
\hline $\begin{array}{l}\text { To } \\
\text { from }\end{array}$ & $\mathrm{D}$ & $E$ & $\mathrm{~F}$ & Supply \\
\hline \multirow[t]{2}{*}{ A } & 6 & 4 & 1 & $50 / 15 / 0$ \\
\hline & & 15 & 35 & \\
\hline B & 3 & 8 & 7 & 40 \\
\hline \multirow[t]{2}{*}{$\mathrm{C}$} & 4 & 4 & 2 & $60 / 0$ \\
\hline & & 60 & & \\
\hline Demand & 20 & $95 / 80 / 20$ & $35 / 0$ & 150 \\
\hline
\end{tabular}

Table 4.1(d). Iteration 3 of example 1

Iteration 4:

In the remaining column, only cell is 8 and allocate $\min (40,20)$. Cross out the column since it reaches zero.

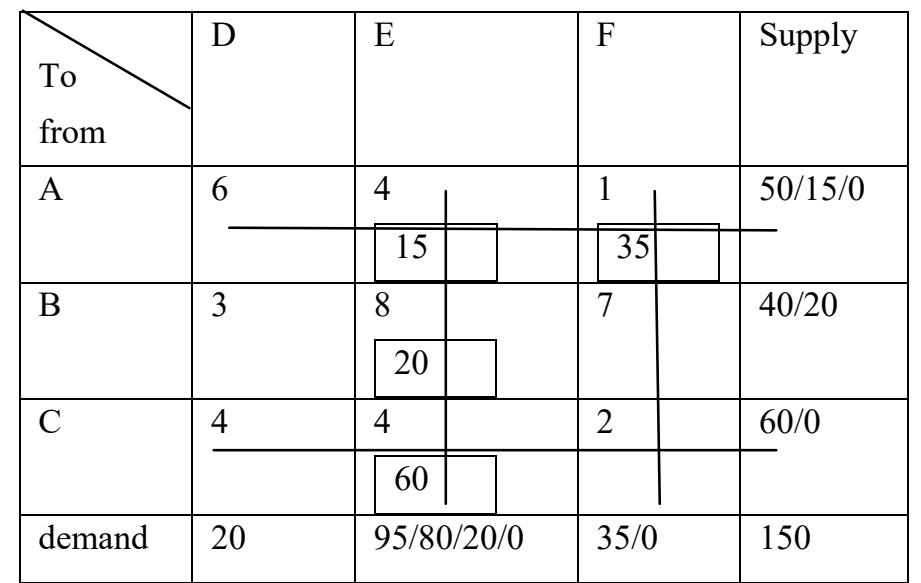

Table 4.1(e). Iteration 4 of example 1 
Iteration 5:

In the remaining row, only cell is 3 and allocate $\min (20,20)$. Cross out the row since it reaches zero.

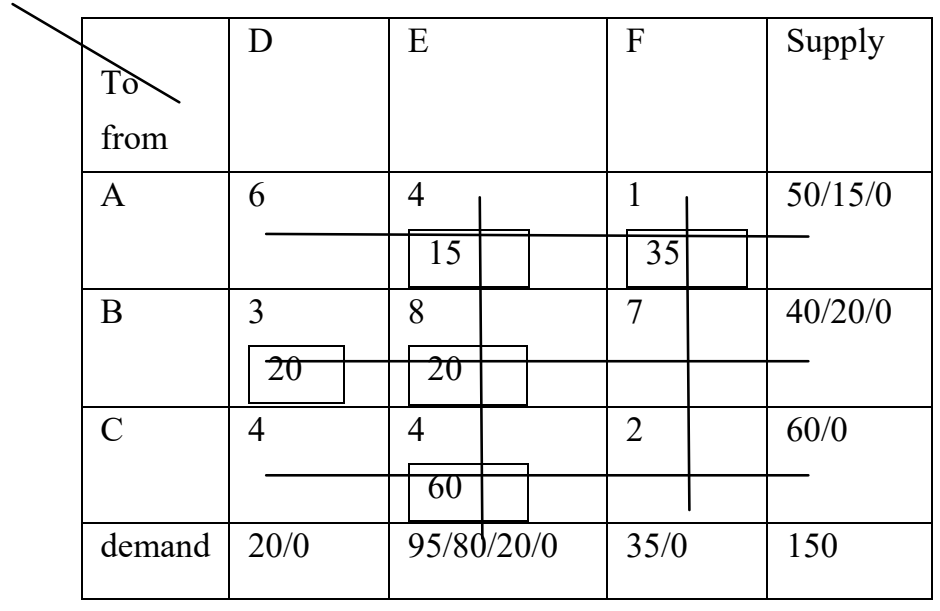

Table 4.1(f). Iteration 5 of example 1

Total Cost: $((4 * 15)+(1 * 35)+(3 * 20)+(8 * 20)+(4 * 60))=$ Tk.. 555

This is a basic feasible solution. The solutions obtained using NCM, LCM, VAM and MODI is 730, 555, 555 and 555 respectively. Hence the basic feasible solution obtained from new method is optimal solution.

\section{Example 2}

A transportation table to calculate the feasible solution to apply our new proposed method is given below:

\begin{tabular}{|l|l|l|l|l|l|}
\hline From & Do & E & F & G & Supply \\
\hline A & 10 & 2 & 20 & 11 & 15 \\
\hline B & 12 & 7 & 9 & 20 & 25 \\
\hline C & 4 & 14 & 16 & 18 & 10 \\
\hline Demand & 5 & 15 & 15 & 15 & 50 \\
\hline
\end{tabular}

Table 4.2(a). Transportation table of example 2. 
Iteration 1:

At first select the upper right cell of given table. Allocate the minimum between available supply and demand (15, 15). Here both row and column reach zero, cross out them.

\begin{tabular}{|l|l|l|l|l|l|}
\hline \multicolumn{1}{|c|}{ From } & D & E & F & G & Supply \\
\hline A & 10 & 2 & 20 & 11 & $15 / 0$ \\
\hline B & 12 & 7 & 9 & 20 & 25 \\
\hline C & 4 & 14 & 16 & 18 & 10 \\
\hline Demand & 5 & 15 & 15 & $15 / 0$ & 50 \\
\hline
\end{tabular}

Table 4.2(b). Iteration 1 of example 2

Iteration 2:

Again select the upper right cell of the remaining cells, allocate the minimum available supply and demand $(25,15)$. Then cross out the column which reaches zero.

\begin{tabular}{|l|l|l|l|l|l|}
\hline \multicolumn{1}{|c|}{ From } & D & E & F & G & Supply \\
\hline A & 10 & 2 & 20 & 11 & $15 / 0$ \\
\hline B & 12 & 7 & 9 & 20 & $25 / 10$ \\
\hline C & 4 & 14 & 16 & 18 & 10 \\
\hline Demand & 5 & 15 & $15 / 0$ & $15 / 0$ & 50 \\
\hline
\end{tabular}

Table 4.2(c). Iteration 2 of example 2 
Iteration 3:

Now select the minimum cell of remaining row, allocate the minimum available demand and supply. Cross out the row which reaches zero.

\begin{tabular}{|l|l|l|l|l|l|}
\hline \multicolumn{1}{|c|}{ From } & D & E & F & G & Supply \\
\hline A & 10 & 2 & 20 & 11 & $15 / 0$ \\
\hline B & 12 & 7 & 9 & 20 & $25 / 10 / 0$ \\
\hline C & 4 & 14 & 16 & 18 & 10 \\
\hline Demand & 5 & $15 / 5$ & $15 / 0$ & $15 / 0$ & 50 \\
\hline
\end{tabular}

Table 4.2(d). Iteration 3 of example 2

Iteration 4:

Proceed the same way we get the following transportation table:

\begin{tabular}{|c|c|c|c|c|c|}
\hline From & $\mathrm{D}$ & $E$ & $\mathrm{~F}$ & $\mathrm{G}$ & Supply \\
\hline A & 10 & 2 & 20 & 11 & \multirow[t]{2}{*}{$15 / 0$} \\
\hline & & & & 15 & \\
\hline \multirow[t]{2}{*}{ B } & 12 & 7 & 9 & 20 & \multirow[t]{2}{*}{$25 / 10 / 0$} \\
\hline & & 10 & 15 & & \\
\hline \multirow[t]{2}{*}{$\mathrm{C}$} & 4 & 14 & 16 & 18 & \multirow[t]{2}{*}{$10 / 5 / 0$} \\
\hline & 5 & 5 & & & \\
\hline Demand & $5 / 0$ & $15 / 5 / 0$ & $15 / 0$ & $15 / 0$ & 50 \\
\hline
\end{tabular}

Table 4.2(e). Iteration 4 of example 2

Total Cost: $((11 * 5)+(9 * 15)+(7 * 10)+(4 * 5)+(14 * 5))=$ Tk.. 460 .

This is a basic feasible solution. The solutions obtained using North West Corner Rule, Row Minima method, Column Minima method are 520, 505, 505 respectively. Hence the basic feasible solution obtained from new method is optimal solution. 


\section{Example 3}

A transportation table to calculate the feasible solution applying our new proposed method is given below.

\begin{tabular}{|l|l|l|l|l|l|l|}
\hline $\begin{array}{l}\text { From } \\
\text { Fo }\end{array}$ & E & F & G & H & I & Supply \\
\hline A & 4 & 0 & 2 & 4 & 4 & 60 \\
\hline B & 2 & 2 & 2 & 2 & 2 & 35 \\
\hline C & 2 & 4 & 2 & 4 & 4 & 40 \\
\hline Demand & 22 & 45 & 20 & 18 & 30 & 135 \\
\hline
\end{tabular}

Table 4.3(a).Transportation table of example 3

Iteration 1:

Select the south-west cell of table. Allocate the minimum between available supply and demand (60, 30). Cross out the column which reaches zero.

\begin{tabular}{|c|c|c|c|c|c|c|}
\hline From & $E$ & $F$ & $G$ & $\mathrm{H}$ & I & Supply \\
\hline $\mathrm{A}$ & 4 & 0 & 2 & 4 & $\begin{array}{l}4 \\
30\end{array}$ & $60 / 30$ \\
\hline B & 2 & 2 & 2 & 2 & 2 & 35 \\
\hline $\mathrm{C}$ & 2 & 4 & 2 & 4 & 4 & 40 \\
\hline Demand & 22 & 45 & 20 & 18 & $30 / 0$ & 135 \\
\hline
\end{tabular}

Table 4.3(b). Iteration 1 of example 3 
Iteration 2:

Find out the minimum cell in the remaining row, and allocate the minimum between available supply and demand (45, 30). Cross out the row which reaches zero.

\begin{tabular}{|l|l|l|l|l|l|l|}
\hline $\begin{array}{l}\text { To } \\
\text { From }\end{array}$ & E & F & G & H & I & Supply \\
\hline A & 4 & 0 & 2 & 4 & 4 & $60 / 30 / 0$ \\
\hline B & 2 & 2 & 2 & 2 & 2 & 35 \\
\hline C & 2 & 4 & 2 & 4 & 4 & 40 \\
\hline Demand & 22 & $45 / 15$ & 20 & 18 & $30 / 0$ & 135 \\
\hline
\end{tabular}

Table 4.3(c). Iteration 2 of example 3

Iteration 3:

Select the minimum cell in the remaining column, and allocate the minimum between available supply and demand (15, 35). Cross out the column which reaches zero.

\begin{tabular}{|c|c|c|c|c|c|c|}
\hline $\begin{array}{l}\text { To } \\
\text { From }\end{array}$ & $E$ & $\mathrm{~F}$ & G & $\mathrm{H}$ & I & Supply \\
\hline A & 4 & \begin{tabular}{l|l}
0 & \\
30 &
\end{tabular} & 2 & 4 & $\begin{array}{l}4 \\
30\end{array}$ & $60 / 30 / 0$ \\
\hline B & 2 & 2 & 2 & 2 & 2 & $35 / 20$ \\
\hline $\mathrm{C}$ & 2 & 4 & 2 & 4 & 4 & 40 \\
\hline Demand & 22 & $45 / 15 \%$ & 20 & 18 & $30 / 0$ & 135 \\
\hline
\end{tabular}

Table 4.3(d). Iteration 3 of example 3 
Iteration 4:

In the remaining row all cells are equal. So we select the cell of that column which number is minimum. Allocate the minimum available demand and supply $(22,20)$. Cross out the row reaches zero.

\begin{tabular}{|c|c|c|c|c|c|c|}
\hline $\begin{array}{l}\text { To } \\
\text { From }\end{array}$ & $\mathrm{E}$ & F & $\mathrm{G}$ & $\mathrm{H}$ & I & Supply \\
\hline \multirow[t]{2}{*}{ A } & \multirow[t]{2}{*}{4} & 0 & 2 & 4 & 4 & $60 / 30 / 0$ \\
\hline & & 30 & & & 30 & \\
\hline \multirow[t]{2}{*}{ B } & 2 & 2 & 2 & 2 & 2 & $35 / 20 / 0$ \\
\hline & 20 & & & & & \\
\hline $\mathrm{C}$ & 2 & 4 & 2 & 4 & 4 & 40 \\
\hline Demand & $22 / 2$ & $45 / 15 \%$ & 20 & 18 & $30 / 0$ & 135 \\
\hline
\end{tabular}

Table 4.3(e). Iteration 4 of example 3

Iteration 5:

Proceeding in the same way, we obtain the final transportation table is given below:

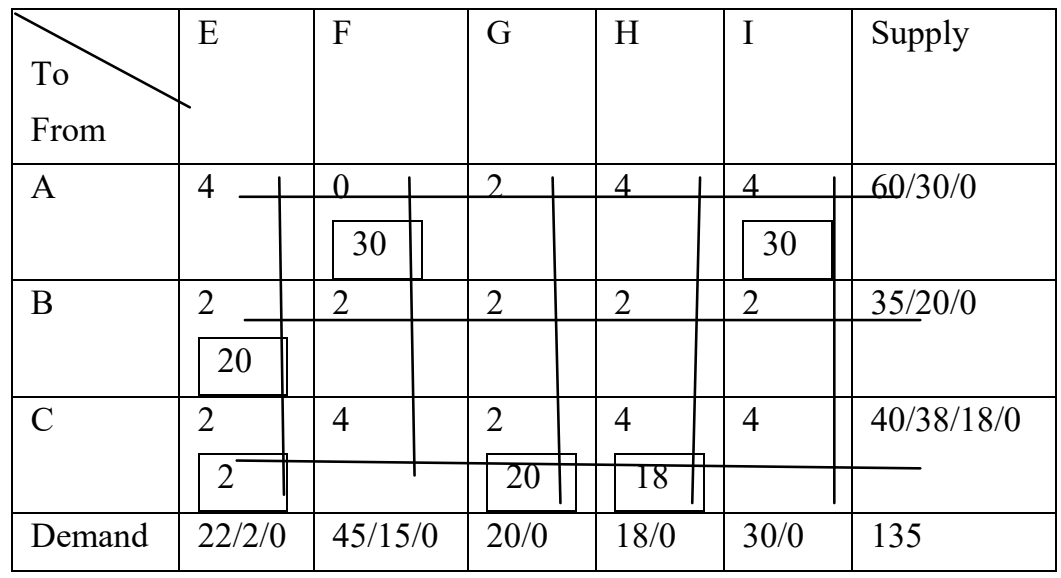

Table 4.3(f). Iteration 5 of example 3

Total Cost: $((4 * 30)+(0 * 30)+(2 * 20)+(2 * 2)+(2 * 20)+(4 * 18))=$ Tk. 305

This is a basic feasible solution. The solutions obtained using North West Corner Rule is Tk.. 318. Hence the basic feasible solution obtained from new method is optimal solution.

\section{Results}

The proposed algorithm provides comparatively a better IBFS solution than those obtained by the traditional algorithms which is either optimal or near to optimal solution. So, this will help to achieve the goal to those who want to maximize their profit by minimizing the transportation cost. We know that the North West Corner Rule is the worst method and the Vogel's Approximation Method is the best. It is observed that our proposed algorithm provides comparatively a better IBFS than those obtained by the North West Corner Rule and is same as the optimal solution obtained by Vogel's Approximation Method. The limitations of the proposed method is that we could not reach the better solution comparatively from the Vogel's Approximation method. 


\section{Suggesstions}

The proposed method cannot give better optimize result compared by Vogel's Approximation Method and in future, it may be extended a modified improve method which can be find the better optimize result obtained by Vogel's Approximation Method.

\section{Conclusion}

The proposed method employed in this paper can be used with good deal of success in solving transportation problems. Besides, it reduced complexities within a shorter period of time via producing a simple and clear solution that could be easily used in other areas for optimizing other problems. This method will be very lucrative for those decision makers who are dealing with logistics and supply chain related issues. Because of the simplicity of this method one can easily adopt it among the existing methods.

\section{Acknowledgement}

The Noakhali Science and Technology University for providing a research fund to complete this work.

\section{References}

Hamdy, A. T. (2013). Operations Research: An Introduction. 9th Edition, ISBN-13: 9780132555937.

Gupta, P. K., \& Mohan, M. (2004). Operations Research. Sultan Chand \& Sons, 12th Edition.

Sharma, J. K. (2005). Operations Research-Theory and applications. Macmillan India (LTD), New Delhi.

Ahmed, M. M., Khan, A. R., Uddin, Md. S., \& Ahmed, F. (2016). A New Approach to Solve Transportation Problems. Open Journal of Optimization, 5, pp. 22-30,

Joshi, R. V. (2015). Optimization Techniques for Transportation Problems of Three Variables, IOSR Journal of Mathematics (IOSR-JM), 9(1), 46-50

Sudhakar, V. J., Arunsankar, N., \& Karpagam, T. (2012). A New approach for finding an Optimal Solution for Transportation Problems. European Journal of Scientific Research, 68, 254-257.

Pandian, P., \& Natarajan, G. (2010). A New Method for Finding an Optimal Solution for Transportation Problems. International J. of Math. Sci. \& Engg. Appls., 4, 59-65. 


\section{Appendix}

\section{CODE BLOCKS Listing of New Proposed Method}

\#include $<$ bits $/$ stdc ++ .h $>$

\#define ROW 101

\#define COLUMN 101

using namespace std;

const int $\mathrm{INF}=1000000000$

int Copy[ROW][COLUMN] $=\{\{0\}\}$;

int main()

\{

ios_base::sync_with_stdio(false);

int row,column, result $=0$;

int Matrix[ROW][COLUMN],Supply[ROW],Demand[COLUMN];

bool visit[ROW][COLUMN];

printf("Enter the number of ROW: ");

scanf("\%d",\&row);

printf("ln");

printf("Enter the number of COLUMN: ");

scanf("\%d",\&column);

printf("\n");

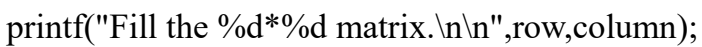

for(int $\mathrm{i}=1 ; \mathrm{i}<=$ row; $\mathrm{i}++)\{$

for(int $\mathrm{j}=1 ; \mathrm{j}<=$ column; $\mathrm{j}++)\{$

scanf("\%d",\&Matrix[i][j]);

\}

\}

printf("\n");

printf("Enter the supply of each row: $\ln \lfloor n ")$;

for(int $\mathrm{i}=1 ; \mathrm{i}<=$ row; $\mathrm{i}++)\{$

scanf("\%d",\&Supply[i]);

\}

printf("\n"); 


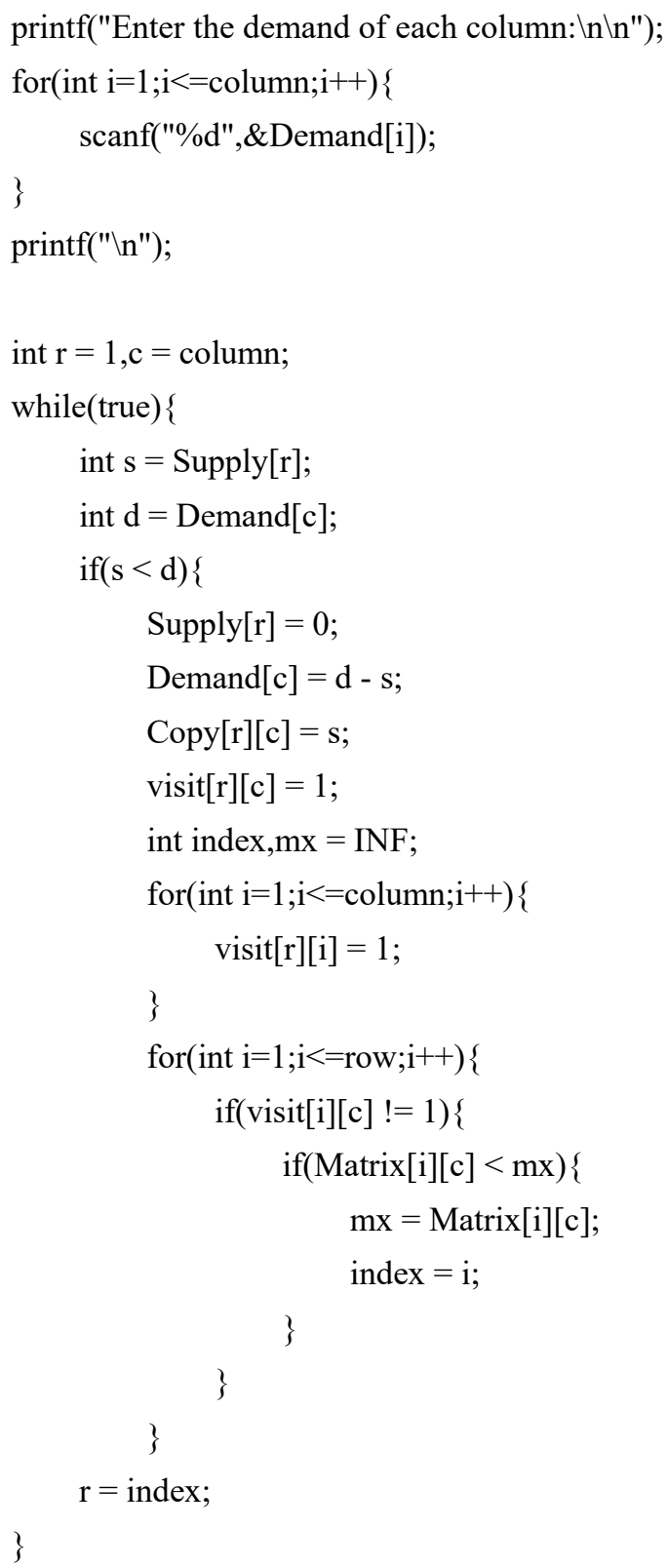




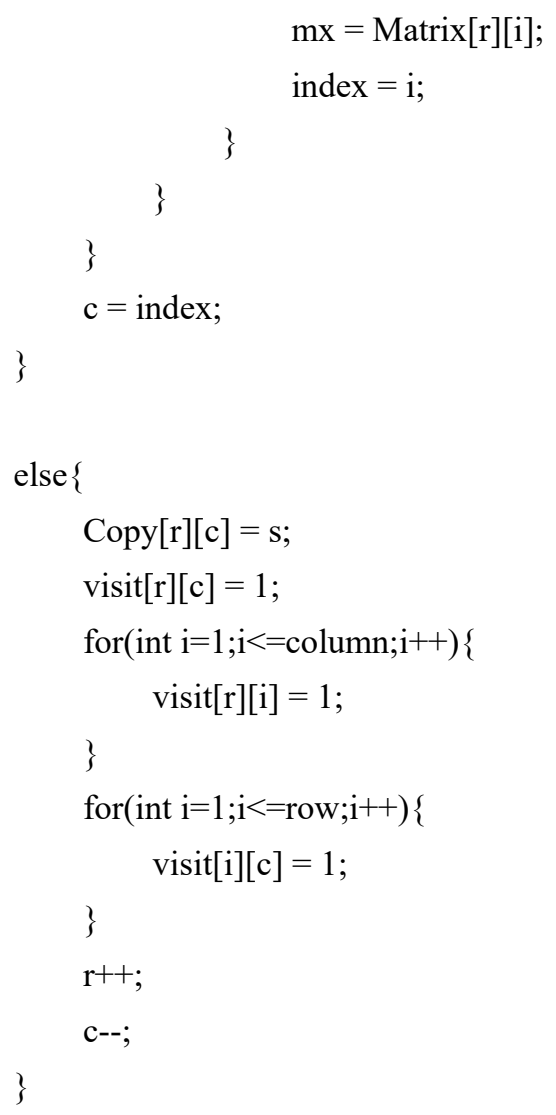




\section{Copyrights}

Copyright for this articleis retained by the author(s), with first publication rights granted to the journal.

This is an open-access article distributed under the terms and conditions of the CreativeCommons Attribution license (http://creativecommons.org/licenses/by/4.0/). 